\title{
Large-bowel obstruction caused by pancreatic tail
}

\section{cancer}

A 60-year-old man presented to our hospital with abdominal pain. Enhanced abdominal computed tomography (CT) revealed a well-demarcated, low-density tumor in the tail of the pancreas ( Fig. 1). ${ }^{18} \mathrm{~F}$-fluorodeoxyglucose positron emission tomography (FDG-PET) showed high uptake in the tumor (standardized uptake value 17) ( Fig.2). Colonoscopy revealed a mass in the descending colon causing marked stenosis ( $\bullet$ Fig.3). Consistent with this finding, the colonoscope could not pass through the obstructed segment. CT colonography revealed an apple-core lesion in the descending colon ( Fig.4), and histological examination of the biopsy samples revealed poorly differentiated adenocarcinoma. A few days later, the patient was admitted with abdominal pain due to acute large-bowel obstruction. Emergency distal pancreatectomy, left hemicolectomy, and partial adrenalectomy and lymph node dissection were carried out. Gross examination of the resected specimen showed a submucosal tumor of the colon with the majority of the tumor residing in the pancreas ( $\bullet$ Fig.5). The patient was diagnosed as having anaplastic pancreatic cancer with osteoclast-like giant cells. Postoperative follow-up at 2 years showed no recurrence.

High accumulation of FDG in FDG-PET is somewhat rare in pancreatic ductal adenocarcinoma due to the scattered distribution of cancer cells [1]. Thus, pancreatic tumors with high uptake should be considered atypical. Anaplastic pancreatic carcinoma is a solid-type tumor with poor prognosis; however, the presence of osteoclast-like giant cells is associated with relatively good prognosis [2]. Acute abdominal pain due to large-bowel obstruction is a rare symptom of pancreatic cancer, and only four cases have been reported to date [3], all of whom died within several months. Thus, extended resection is not recommended in patients with pancreatic cancer presenting with large-bowel obstruction. However, in patients with colonic obstruction due to pancreatic cancer and atypical radiological findings, aggressive surgery should be considered to improve prognosis.

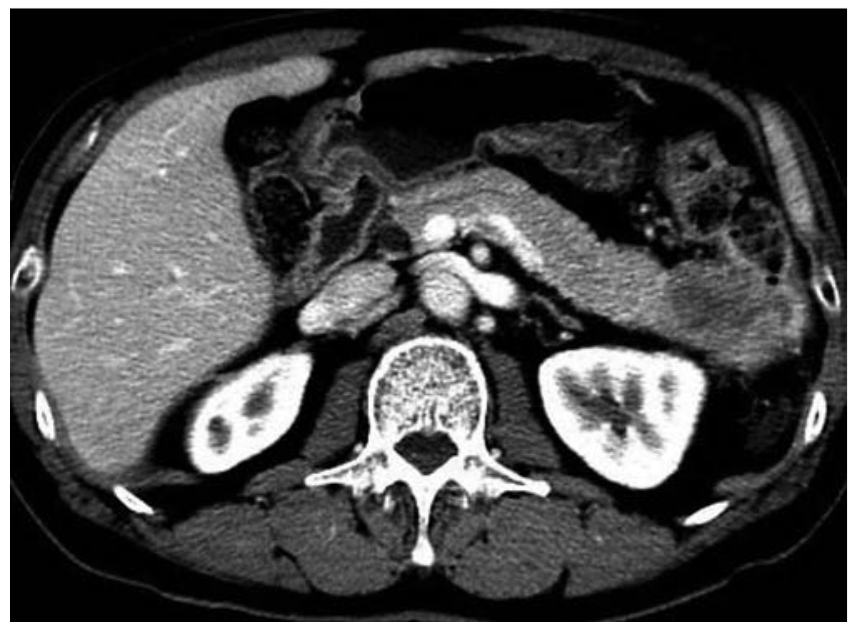

Fig. 1 Abdominal enhanced computed tomography $(\mathrm{CT})$ view of a well-demarcated, low-density tumor, about $4.5 \mathrm{~cm}$ in diameter, in the tail of the pancreas in a 60 -yearold man with abdominal pain.

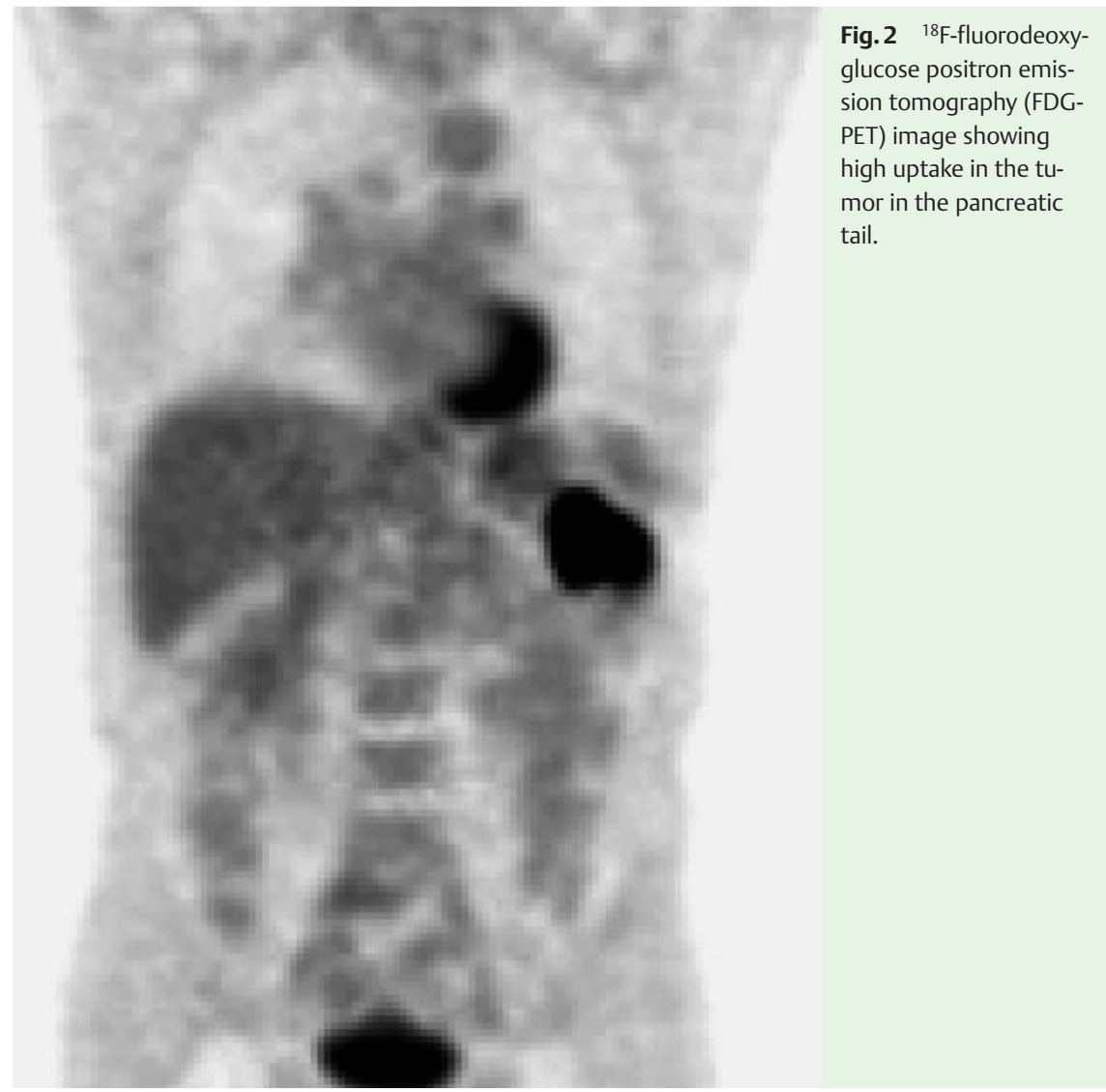

Endoscopy_UCTN_Code_CCL_1AD_2AJ

Competing interests: None 


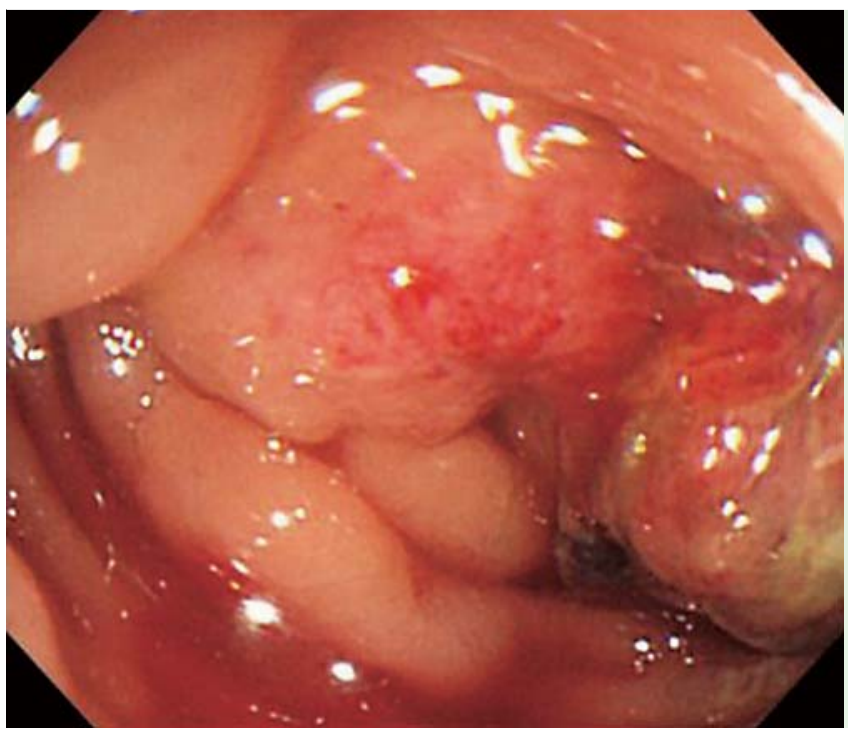

Fig. 3 Colonoscopic view showing tumorous obstruction in the descending colon.

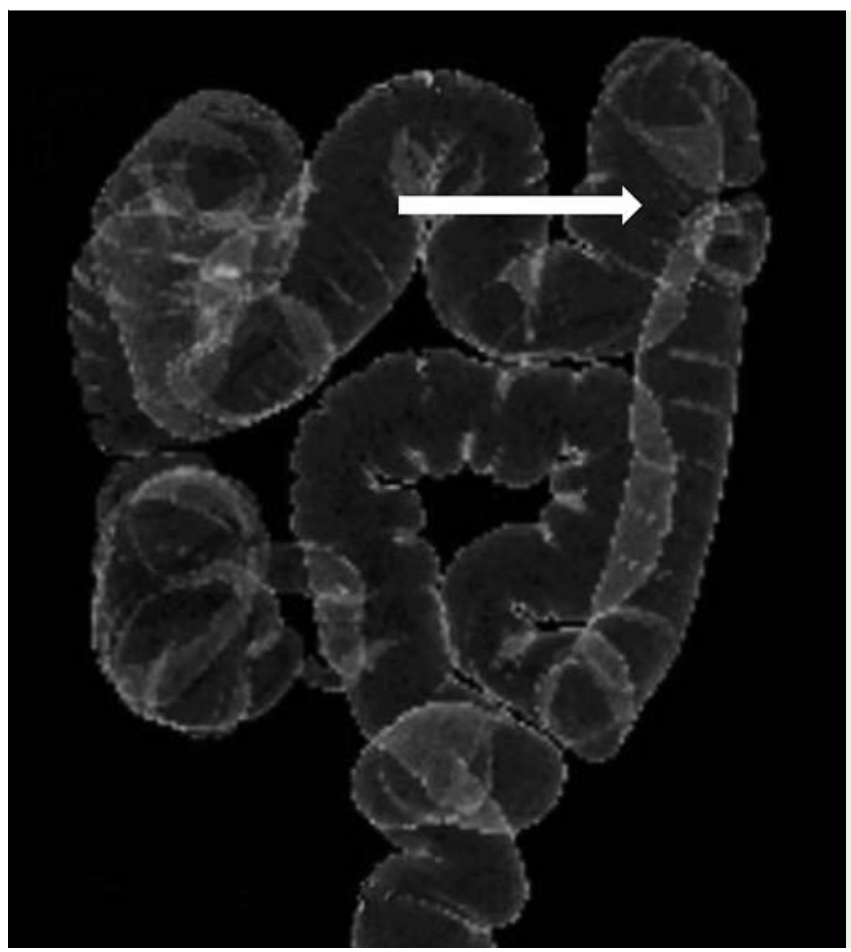

Fig. 4 Computed tomography (CT) colonography showing severe stenosis in the descending colon.

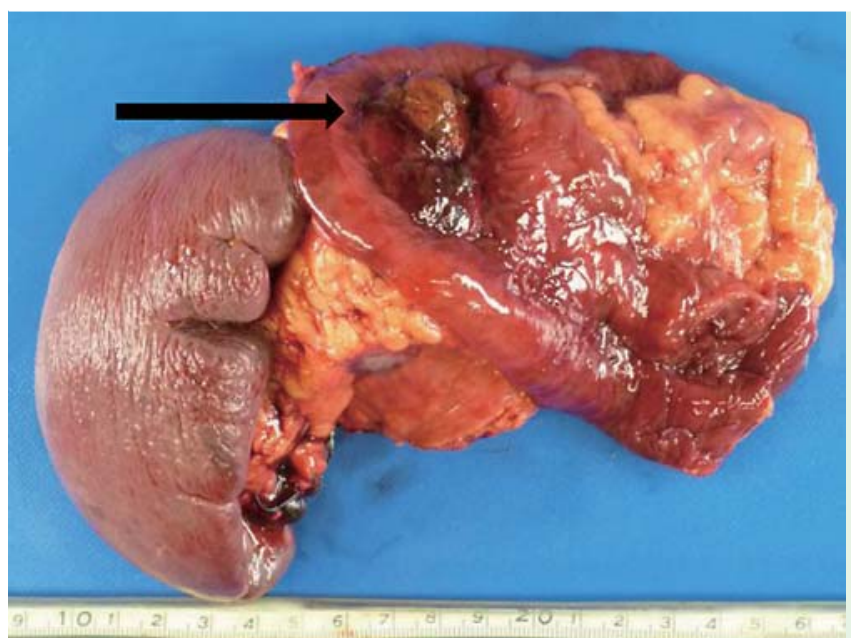

Fig. 5 Resected specimen showing a submucosal tumor of the colon with the majority of the tumor residing in the pancreas.
K. Izuishi ${ }^{1}$, T. Sano', Y. Okamoto ${ }^{1}$, H. Mori ${ }^{2}$, M. Oryu' ${ }^{2}$, T. Maeta ${ }^{2}$, K. Ebara ${ }^{1}$

${ }^{1}$ Department of Gastroenterological Surgery, Federation of Public Services and Affiliated Personnel Aid Associations, Takamatsu Hospital, Takamatsu, Kagawa, Japan

2 Department of Internal Medicine of Gastroenterology, Federation of Public Services and Affiliated Personnel Aid Associations, Takamatsu Hospital, Takamatsu, Kagawa, Japan

\section{References}

1 Izuishi K, Yamamoto Y, Sano T et al. Impact of 18-fluorodeoxyglucose positron emission tomography on the management of pancreatic cancer. J Gastrointest Surg 2010; 14: $1151-1158$

2 Strobel O, Hartwig W, Bergmann F et al. Anaplastic pancreatic cancer: Presentation, surgical management, and outcome. Surgery 2011; 149: 200-208

3 Griffin R, Villas B, Davis C et al. Carcinoma of the tail of the pancreas presenting as acute abdomen. JOP 2012; 13: 58-60

\section{Bibliography}

DOI http://dx.doi.org/

10.1055/s-0032-1310075

Endoscopy 2012; 44: E368-E369

(c) Georg Thieme Verlag KG

Stuttgart · New York

ISSN 0013-726X

\section{Corresponding author}

\section{K. Izuishi}

Department of Gastroenterological Surgery Federation of Public Services and Affiliated Personnel Aid Associations

Takamatsu Hospital

4-18 Tenjinmae

Takamatsu

Kagawa 760-0018

Japan

Fax: +81-87-8350793

izuishi@kkr-ta-hp.gr.jp 